\title{
University of Ottawa Vertical Mentorship Program: Improving Engagement through Innovation
}

\author{
Christopher Russell, BHSc${ }^{1}$; Iuliia Povieriena, $\mathrm{MSc}^{1}$; Marianne Levesque ${ }^{1}$
}

${ }^{1}$ Faculty of Medicine, University of Ottawa

\section{A B STRACT}

Objective: To describe three identified program gaps (attendance/engagement, program understanding, issue identification/resolution), and present data from surveys that may help assess the impact of innovation.

Methods: Survey responses, event attendance, and subjective observations, were compared between the 2014-2015 and 20152016 academic years, providing indirect measures of gap closure.

Results: Mid-year survey response rate was double that of end of year surveys $(n=133)$, and increased responses from second-year coordinators and mentors were seen in both the 2015-2016 surveys. Dessert night attendance increased from 2014 to 2015 (383 to 436). End of year event numbers decreased year-to-year (163 to 115). Only 5.9\% of students did not attend events due to a lack of interest in the program. Mid-year surveys identified three groups with difficulties communicating. Knowledge of available resources in mentors rose by $5 \%$ between years, and by $55 \%$ in second-year coordinators. 12 of the 52 mentorship groups used Facebook to engage and plan joint activities. The nominations received at the end of the year, and survey comments, focused beyond topics of career mentoring, and expanded to the impact of the field on life, life in medicine, and family.

Conclusion: Identifying gaps in a program such as the Vertical Mentorship Program (VMP), through eliciting feedback from those participating may be challenging. Establishing innovations based around identified gaps may be an effective way to improve participants' experiences and overall functioning of the program.

\section{RÉ S U Ḿ}

\begin{abstract}
Objectif: Décrire 3 lacunes du programme de mentorat vertical (participation/engagement, compréhension du programme, identifications des problèmes/résolution), et présenter les données de sondages qui pourraient aider à évaluer l'impact de l'innovation.

Méthodes: Les réponses aux sondages, la participation aux évènements et les observations subjectives ont été comparées entre les années scolaires 2014-2015 et 2015-2016, servant ainsi de mesures indirectes pour le comblement des lacunes.

Résultats: Le taux de réponse aux sondages du milieu de l'année était deux fois plus élevé que celui à la fin de l'année ( $\mathrm{n}=133$ ), et une hausse du taux de réponse des coordonnateurs de deuxième année et des mentors a été observée dans les sondages de $2015-2016$. La participation à la soirée des desserts a augmenté de 2014 à 2015 (383 à 436). Le nombre de participants présents à l'évènement de fin d'année a diminué d'année en année (163 à 115). Seulement 5,9 \% des étudiants n'ont pas participé aux évènements à cause d'un manque d'intérêt. Les sondages semestriels ont révélé 3 groupes de mentorat qui ont éprouvé des difficultés de communication. Les connaissances des mentors au sujet des ressources disponibles ont augmenté de $5 \%$ au fil des années, et de $55 \%$ chez les coordonnateurs de deuxième année. Douze des 52 groupes de mentorat ont utilisé Facebook pour communiquer et pour planifier des activités. Les nominations reçues en fin d’année ainsi que les commentaires provenant des sondages étaient axés sur des sujets au-delà du mentorat professionnel, et touchaient à l'impact de la médecine sur la vie personnelle, et à la famille.

Conclusion: II peut être un défi d'identifier les lacunes d'un programme, tel le programme de mentorat vertical, en utilisant la rétroaction des participants. Malgré cela, les lacunes identifiées peuvent possiblement servir de tremplin pour effectuer des changements qui améliorent l'expérience des participants et le fonctionnement général du programme.
\end{abstract}

\section{INTRODUCTION}

The University of Ottawa Faculty of Medicine's Student Affairs Office (SAO) Vertical Mentorship Program (VMP) has been a longstanding foundation in medical education. Even if no official records of the foundation of this program exist, anecdotes lead to the belief that a group of alumni in the 1980s may be responsible for its creation. Such a program was first designed recognizing the importance of guidance and support for students Keywords: Medical Education; Mentorship during medical training. Stress reduction, improved self-esteem, career development, and research productivity are amongst the many benefits known to mentorship [1,2]. The VMP aims to offer students opportunities to develop a realistic perspective of the implications of a medical career, to network within the medical community, and to promote health and well-being.

Ottawa's program was structured to fulfill the above intents through student-student and mentor-student interactions. Ot- 
tawa's VMP is formed of 52 different mentorship groups, each composed of one to two mentors, and three to four students from each academic year. All mentors are volunteers, and incoming first-year students are automatically matched to a mentorship group before starting class. This format aims to promote interactions between students of different academic years, and physicians, which ultimately contributes to their adaptation and growth through medical school.

The SAO facilitates this structure by assigning two students to become VMP coordinators, one from each language stream, during their second year of medical school, to help organize events and mentorship groups. In 2015, a student communications coordinator was added as a third position to the student VMP team. Within individual mentorship groups, second-year group coordinators are selected through self or group nomination, serving as a link between the VMP coordinators and the mentorship groups. No formal assessment of the VMP performance exists. A survey distributed by the SAO at the end of the 2014-2015 academic year identified several gaps. Student attendance and engagement, understanding of roles and responsibilities of all parties, and identification and resolution of issues were among major themes identified as requiring amelioration. Inappropriate or unrealistic expectations from both mentees and mentors towards mentorship have been observed in other programs to be a barrier for effective and satisfying mentorship experiences [1,3]. Time commitments, as well as negative or neutral perceptions of the value of such program have also been barriers to participation for students and mentors of certain American medical schools [1]. It was also recognized that evaluation of mentorship programs is often challenging, due to unclear expectations from both parties, and often informal or unstructured setup [1].

The purpose of this study was to describe the gaps identified in the 2014-2015 academic year, the innovations that were implemented to address these gaps, as well as present gathered data from surveys that may provide some indirect evidence towards addressing gaps, and lay the foundation for future, more rigorous, analysis of program function.

\section{Approaching the Gaps}

From the completed surveys that were distributed during the 2014-2015 End of the Year and Awards Night, three major gaps were identified, and innovations were developed with the intention of approximating those gaps (Figure 1).

\section{Event Attendance and Program Engagement}

The 2014-2015 survey showed that quality communication between students and mentors within some groups was not always present. This was addressed by increasing frequency

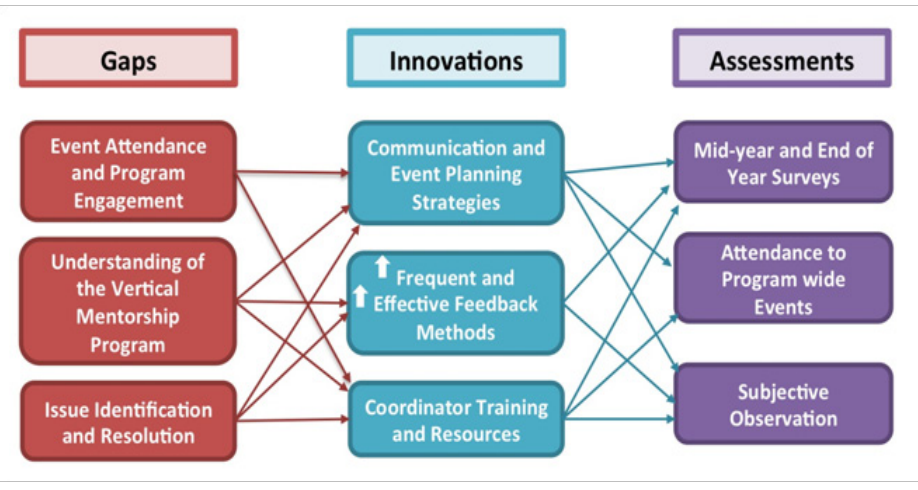

Figure 1: Outline of the process of using innovations to address gaps, and the assessment measures used to assess their effectiveness.

and improving quality of email communications, increasing the program's social media presence, and providing support to second-year group coordinators and mentors through a training session.

Increased email communications served as a constant reminder of the program's existence, and offered opportunities for mentors and second-year coordinators to contact program coordinators. In order to increase social media presence, the VMP communications coordinator created and maintained a closed VMP Facebook group and submitted blog posts to the Aesculapian Society website. The Facebook group was also intended to foster a more collaborative environment and make inter-group activities more easily accessible. All initiatives were intended to increase attendance at program wide events.

\section{Understanding of the VMP}

From survey results, it was inferred by program coordinators that the level of understanding of the program may be related to limited knowledge of the VMP vision and goals. This was demonstrated by a general unawareness of available resources, as well as a shared interest between mentors, second-year coordinators, and members of the SAO of having joint meetings in order to discuss how to improve students' mentorship experience.

In an attempt to answer the needs of all participants (i.e. students, second-year coordinators, and mentors) a mentor training session was provided by Dr. Karima Khamisa (a senior mentor), and a second-year coordinator training session was provided by the VMP student team in September 2015. Related resources were made available to both mentors and students. These included a PowerPoint presentation with a review of the vision and goals of the VMP, a review of their respective roles, and strategies to a successful year. Access to the SAO website, the VMP Facebook group, and program coordinators contact 
information was also discussed.

The objective of the session was for the second-year group coordinator to optimize their organization and conflict resolution skills. Emphasis was placed on their importance as liaisons within groups, and their role in contacting program coordinators if they had any questions or concerns at any point in time.

\section{Issue Identification and Resolution}

The 2014-2015 survey revealed that there might have been long standing issues within groups (i.e. low satisfaction rates, poor communication, poor student attendance, and poor mentor availability) that had remained unaddressed for an undetermined period of time. To address this specific problem, the VMP coordinators emphasized the importance of prompt and open communication with the VMP student team during the second-year coordinator training session. Regular (approximately monthly) email communications to all parties, as mentioned above, also served as reminders that the VMP team was always available to support and help concerned individuals in delicate group situations.

A mid-year survey was also distributed electronically in December 2015 in order to get timely feedback. It was the first time a midyear survey was implemented. Its main focus being to ensure that groups experienced no major issues with communication or functioning, and that no problems remained unresolved.

\section{METHODS}

An abbreviated version of the 2014-2015 survey was created, removing questions that assessed very specific topics of discussion in order to make the length more manageable. The abbreviated surveys assessed; number of group events, communication between parties, mentorship content and overall satisfaction, knowledge of resources, as well as several comment areas throughout the survey for students or mentors to expand on their answers. This survey was distributed both electronically and in paper form during the 2016 End of the Year and Awards Night. Descriptive analysis of the results are presented as described below, with the intent of creating a foundation for future, more rigorous analysis of program function to occur.

Survey responses, event attendance rate, as well as subjective observations were compared between the 2014-2015 and 2015-2016 academic years, providing indirect measures of assessment for the identified gaps. Survey response rates and attendance at program-wide events were compared to assess program engagement and student attendance. Students' reasons for not attending were also taken into account.
The level of understanding of the VMP was assessed by mentors and second-year coordinators' indicating "yes" or "no" to knowledge of available resources, as had been assessed in previous years. Groups' social media engagement, survey comments, and content of award nominations, were also subjectively reported.

Issue identification and resolution was assessed by quantifying the issues identified on mid-year surveys, as well as knowledge of available resources for groups to access.

Finally, subjective observations and assessments of student comments, questions, and concerns provided us with more information concerning the functioning of groups as well as the program as a whole in relation to the three gaps investigated.

\section{RESULTS}

Survey response rates were compared between $2014-2015$ end of the year surveys, and 2015-2016 mid-year and end of the year surveys. While end of the year survey completion decreased by 3 respondents from May 2015 to May 2016 (69 to 66), there was the highest participation rate of all three stakeholders on the mid-year survey ( $n=133$ of approximately 700$)$. Furthermore, both student coordinator and mentor survey response rates increased from the end of the year 2014-2015 survey to both 2015-2016 surveys (Figure 2).

To further explore the engagement of students and mentors, attendance numbers at the two program wide events are reported. At Dessert Night, the attendance rate increased from September 2014 to September 2015 (383 to 436). When examining the End of the Year and Award Night, numbers decreased from May 2015 to May 2016 (163 to 115).

Looking at student engagement and perception of the VMP on an individual basis, the 2015-2016 survey allowed students to expand on why they did not attend certain events. $5.9 \%$ of students did not attend events due to a lack of interest in the program; the remaining students did not attend due to schedule conflicts, with $41.2 \%$ of students citing clerkship responsibilities (Figure 3 ). Furthermore, 187 students and mentors had joined the Facebook group by May 2016, and 12 of the 52 mentorship groups were using the group to engage with other groups and plan joint activities or share ideas.

To explore the gap of issue identification and resolution, midyear 2015-2016 survey results were gathered to determine issues to be identified prior to the year's end. Three groups were identified as having difficulty contacting their mentor effectively as expressed by their second-year coordinator in the survey. Four students reported that their groups had not yet met. 


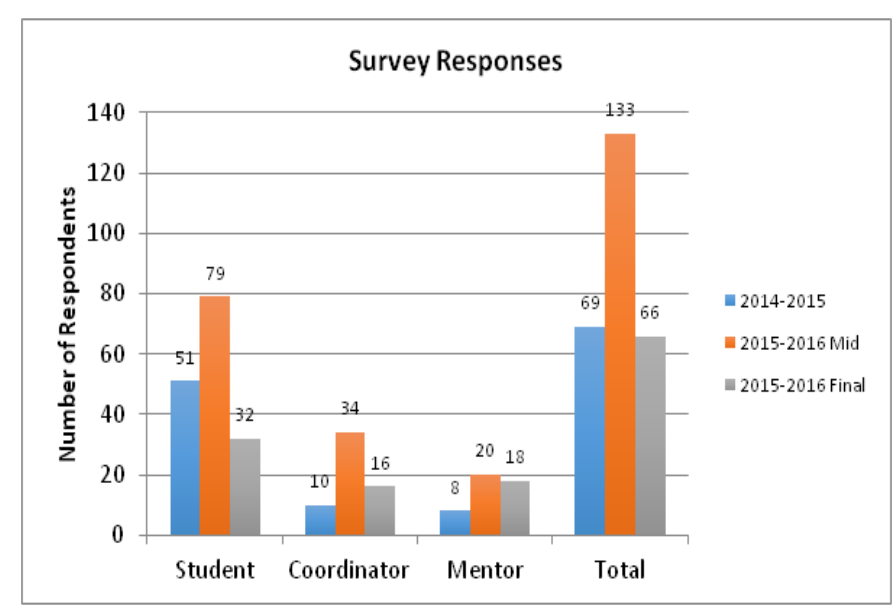

Figure 2: Comparison of the rates of survey responses received from students, second-year coordinators, mentors, and in total for surveys distributed from May 2015 to May 2016.

To explore a given group's ability to address issues that arose, we compared knowledge of mentors and second-year coordinators of available program resources, using a simple yes/no question related to resources existence. Knowledge of available resources in mentors rose by $5 \%$ between the two academic years, and by $55 \%$ in second-year coordinators. The metric (i.e. knowledge of available resources) was also used as an indicator of increased understanding of the Vertical Mentorship Program.

Finally, several subjective factors were compiled as a means of exploring the innovations throughout the year. All three student coordinators that comprised a part of the VMP team had been contacted several times throughout the year by second-year coordinators to address problems, often informally over Facebook personal communications or in person, as encouraged during the training session at the beginning of the year. It was also noted, through subjective observation, observing the Facebook group, as well as anecdotally from students and survey comments, groups had taken to participating in multi-group events, allowing for a larger range of activities and student-mentor interactions. Furthermore, in the end of the year survey comments and nominations received for mentor awards, there were many comments related to VMP goals, including; work life balance, impact of career on family life, mental health and wellness, and life outside of medicine. With regards to career mentoring, several mentors stated they were happy to connect students with physicians in their particular field of interest. Student comments in mentor nominators for awards expressed gratitude towards the mentors for their ability to foster discussion on a wide variety of topics, and give honest advice on realities of the profession.

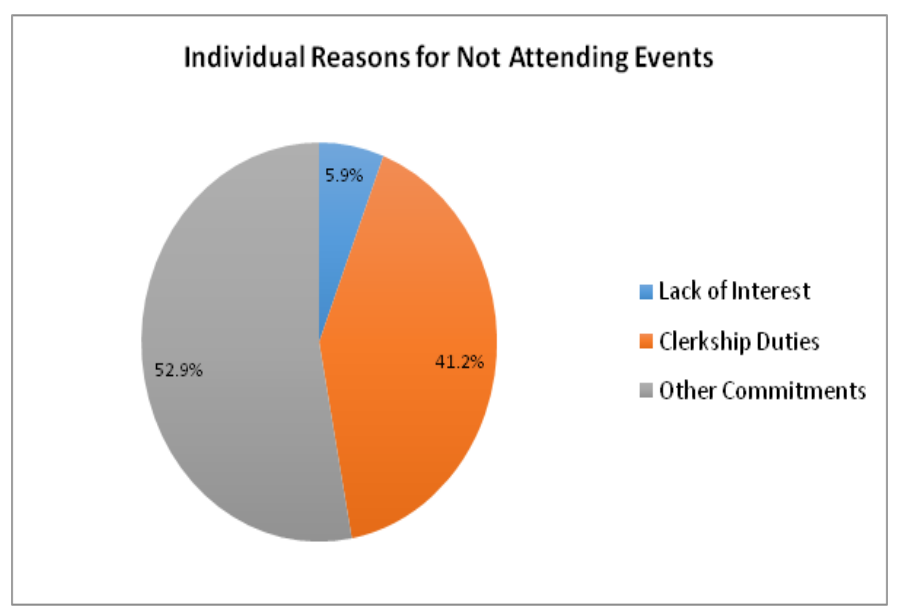

Figure 3: Depiction of the reasons listed by students as to why they did not attend mentorship events, $n=17$ (Lack of interest $=5.9 \%$, Clerkship duties $=41.2 \%$, Other commitments $=52.9 \%$ ).

\section{DISCUSSION}

\section{Event Attendance and Program Engagement}

Overall survey response rates decreased from the 2014-2015 to the 2015-2016 end of the year surveys, however, the 20152016 mid-year survey had nearly double the response rate of either end of the year survey. Furthermore, the response rates from second-year coordinators and mentors both increased on both 2015-2016 surveys compared to the previous year. While it would be ideal if all participants of the program responded to provide their opinion and feedback of the program, given that second-year coordinators are in charge of running their individual groups, and that mentors are key stakeholders in the functioning of groups, having increases in both of their response rates was seen as a positive finding. Providing electronic versions of the surveys as opposed to paper copies used in previous years, increasing email reminders regarding them, and highlighting the importance of feedback to second-year coordinators and mentors during their respective training sessions may have played a positive role in this participation increase.

The rise in attendance numbers at Dessert Night could be attributed to several initiatives, including: Increased frequency of email communications, and social media reminders. These same strategies were applied for the End of the Year and Award Night; unfortunately attendance rates were seen to decline from the previous year. Certain factors may have played a role in this decline, including that a major interest group event took place during the same evening. The event also occurred during Licentiate of the Medical Council of Canada (LMCC) examinations period, which decreased the likelihood of 4 th year students attending. 
Students seemed to have prioritized career related events over a mentorship and wellness event. As is consistent with the literature, a significant proportion of students unable to attend mentorship events mentioned other commitments, including academic obligations $[1,4]$.

In reporting students' rationale for event nonattendance, it was promising to see that only a minority $(5.9 \%)$ reported lack of interest. Furthermore, it was encouraging to see 12 groups engage on the Facebook group as it was suggested during second-year coordinator and mentor training sessions.

Even though 2016 End of the Year and Awards Night's attendance rate was lower than expected, rise in survey response rates and Dessert Night attendance, having schedule conflicts as being the most common barrier to event attendance, and all parties using proposed tools may indicate a higher level of engagement from all parties. Future work could continue to track attendance rates and response rates, and allow for a better understanding of influential factors on program attendance and engagement.

\section{Understanding of the Vertical Mentorship Program}

Knowledge of available resources rose from the previous year for both second-year coordinators and mentors. This may be attributable to the second-year coordinator and mentor training sessions organized in September 2016.

As a new initiative, 12 mentorship groups and 187 members utilized the Facebook group, however, it will likely take time before being utilized by all members of the program. Initially, it was only available to members using a University of Ottawa Gmail address, which was preventing some mentors from joining. In the posts shared on the group, values of the mentorship program were evident, with groups collaborating and sharing experiences. The increased social media visibility of the program allowed another avenue to access information concerning the program as well as additional means to contact the VMP program coordinators.

End of the year survey comments and nominations received for mentor awards contained many comments reflective of students understanding of the purpose of the VMP. The focus was to more broadly cover the program's goals by expanding the wide variety of topics that mentors could offer advice on. The comments appeared to reflect this, along with high mentor and student engagement in these topics.

\section{Earlier Issue Identification}

The feedback elicited through mid-year survey feedback intended for solutions to be proposed and implemented during the second half of the year in order to improve both mentor and mentee experience. Each student part of the VMP team were also approached several times throughout the year by secondyear coordinators concerning different group conflicts and other questions. The second-year coordinators' training session at the beginning of the year may have promoted more open communication between the VMP team and second-year coordinators.

Issue identification was also felt to be aided by the introduction of electronic survey compared to paper copies used in previous years. This allowed for easier survey completion, as well as survey analysis, and captured the responses of students not physically present at events. A $53 \%$ increase in resource awareness in the second-year coordinators may have reduced the need to contact program coordinators for assistance, due to students have the tools to address issues themselves.

\section{Limitations}

Measuring gap closure subjectively limits the application of our findings. Assessing the identified gaps was challenging to do through routine program surveys, as no specific questions were aimed at respondents perceived effectiveness of the innovations. The assessment of the related innovations was derived from indirect program sources of feedback. Finally, while the mid-year survey accomplished its goal by identifying issues promptly, follow-up measures were not well established. Issue resolution strategies should have been in place prior to survey implementation, including an option on the survey to have VMP student coordinators contact the group if the participant wished.

\section{CONCLUSION}

Identifying gaps in a program such as the VMP, through eliciting feedback from those participating may be challenging. Engagement and participation, understanding of the program and issue identification and resolution, were identified as areas of needed improvement. Consequently, this allowed for the development of innovations in an attempt to address these gaps, including; training for stakeholders, social media use, increased communication, and creation of a communication coordinator. Future work could focus on identifying the effectiveness of individual innovations to establish which innovations should continue to be developed. Direct assessments of innovations, rather than the inferred assessments presented, would allow for the significance of innovations to be appreciated. Furthermore, more statistically rigorous analysis of these future works would allow for assessment of program function and improvement over time.

\section{ACKNOWLEDGEMENTS}

We would like to thank Dr. Louise Laramée and Dr. Kay-Anne Haykal for their guidance on this project, as well as their involvement and dedication with the University of Ottawa Faculty of 


\section{Research}

Medicine VMP.

\section{REFERENCES}

1. Fornari A, Murray TS, Menzin AW, Woo VA, Clifton M, Lombardi M, Shelov S. Mentoring Program Design and Implementation in New Medical Schools. Med Educ Online. 2014;19(1):1-8.

2. McKenna AM , Straus SE. Charting a Professional Course: A Review of Mentorship in Medicine. J Am Coll Radiol. 2011;8(2):109-112.

3. Oliver S, Gallacher L, Collins K, Haddock R, Mcauley L, Taylor H. Limitations of Medical Student Mentor Programmes. Clin Teach. 2015;12(3):220.

4. Sambunjak D, Straus SE, Marušić A. Mentoring in Academic Medicine: A Systematic Review. JAMA. 2006;296(9):1103-1115. 